\title{
CONHECIMENTO E PRÁTICA DE PROFESSORES DO ENSINO BÁSICO EM EDUCAÇÃO AMBIENTAL E SAÚDE
}

\author{
Haryanna de Oliveira Arantes ${ }^{1}$ \\ Silvia Carla da Silva André Uehara²
}

Resumo: Este estudo teve como objetivo analisar o conhecimento e a prática de professores do ensino básico sobre educação e saúde ambiental. Trata-se de uma pesquisa descritiva e de abordagem qualitativa, realizada em seis escolas de ensino fundamental de São Carlos-SP, Brasil, com 49 professores. Os dados foram coletados por meio de grupo focal e analisados por meio da análise temática. Os professores apresentaram dificuldades para definir os conceitos de educação e saúde ambiental e para descrever as atividades práticas. Assim, torna-se necessária a inserção da temática na formação inicial dos professores e implementação de estratégias de educação permanente a fim de ampliar as ações em educação e saúde ambiental.

Palavras-chave: Educação em Saúde, Educação Ambiental; Saúde Ambiental, Promoção da Saúde, Saneamento Básico.

Abstract: This study aimed to analyze primary education teachers' knowledge and practice in environmental education and health. It is descriptive and qualitative research, carried out in six elementary schools in São Carlos-SP, Brazil, with 49 teachers. Data were collected through a focus group and analyzed using thematic analysis. Teachers found it difficult to define the concepts of environmental education and health and to describe practical activities. Thus, it is necessary to insert the theme in the initial training of teachers and implement permanent education strategies to expand education and environmental health actions.

Keywords: Health Education, Environmental Education; Environmental Health; Health Promotion, Basic Sanitation.

\footnotetext{
1 Universidade Federal de São Carlos. E-mail: haryanna.arantes@gmail.com, Link para o lattes: http://lattes.cnpq.br/0164408645170435

2 Universidade Federal de São Carlos. E-mail: silviacarla@ufscar.br, Link para o Lattes: http://lattes.cnpq.br/3903413440784581
} 


\section{Introdução}

O aumento populacional associado ao crescimento urbano desordenado contribui diretamente para o aumento do consumo, e, consequentemente, para uma demanda industrial elevada e uso excessivo dos recursos naturais. Temse em vista que o crescimento desordenado e descontrolado associado a ausência de Educação Ambiental (EA) potencializam a contaminação da água, ar e solo, impactando diretamente na saúde da população, sobretudo na saúde das crianças (PHILIPPI; MALHEIROS, 2005).

Estima-se que $26 \%$ da população mundial são crianças e representam o grupo de maior vulnerabilidade quanto aos impactos ambientais à saúde e cerca de $30 \%$ das doenças existentes acometem, em sua maioria, crianças menores de 5 anos (PERLOTH; BRANCO, 2017).

O baixo investimento em recursos sanitários no Brasil repercute diretamente sobre a saúde pública, que tem registrado 400 mil internações a cada ano devido a complicações diarreicas, especialmente em crianças de até 5 anos, estimando um custo anual de $\mathrm{R} \$ 140$ milhões ao Sistema Único de Saúde (SUS); recursos que poderiam ser destinados a universalização dos serviços de esgotamento sanitário (SILVA, 2017).

A causa de óbitos de crianças menores de 5 anos por diarreia ocupa a sétima posição das maiores taxas de mortalidade infantil no Brasil e pode estar associada às condições ambientais e ser responsável por 1.761 óbitos ao ano (FRANÇA et al., 2017). As doenças respiratórias relacionadas à poluição do ar e mudanças climáticas são as principais causas de internação e morbimortalidade no mundo, sendo o principal fator de risco associado à incidência e hospitalização de crianças por essas doenças no país (BEBBER et al., 2020).

Nesse cenário, o processo educativo ganha notoriedade, uma vez que contribui para uma maior compreensão das pessoas sobre as causas e efeitos da relação entre saúde e ambiente, além de enfatizar a corresponsabilidade, bem como os direitos e deveres na busca de soluções e alternativas para minimização de seus impactos na saúde (REIGOTA, 2009).

Na prática, tanto a EA como a educação em saúde integram um mesmo processo de ensino-aprendizagem, ou seja, visam a melhoria das condições de saúde das pessoas, pois cada vez mais torna-se evidente a inter-relação entre o meio ambiente e o nível de saúde da população. A Política Nacional de Educação Ambiental (PNEA) entende que a EA compreende processos pelos quais os indivíduos e coletividade constroem valores sociais, conhecimentos, habilidades, atitudes e competências direcionadas para a preservação do meio ambiente, considerado essencial para a qualidade de vida (BRASIL, 1999).

A escola tem função primordial no processo de ensino-aprendizagem, sendo essencial que questões problematizadoras relacionadas à promoção, prevenção e riscos à saúde sejam abordadas no cotidiano escolar (SILVA, 2016). Nesse contexto, destaca-se o papel dos professores na formação dos 
alunos, despertando-os sobre os seus papéis no que se refere à relação entre meio ambiente e saúde. Os professores são mediadores de informações e personagens essenciais na transformação e alcance da sustentabilidade ambiental, social e econômica.

O desenvolvimento de ações efetivas para a promoção da saúde realizada pelos professores, exige conhecimento e envolvimento com a realidade escolar e da comunidade em que os alunos estão inseridos, bem como a participação em atividades de educação permanente, de forma a capacitarem para trabalhar a saúde de forma transversal e eficaz, superando o enfoque higienista (CARRARO, 2019).

Estudos sobre a inserção da EA no ensino formal, bem como a temática relacionada sobre Saúde Ambiental (SA) apresentam lacunas, uma vez que não mostram as dificuldades e fragilidades enfrentadas pelos professores para o desenvolvimento desse assunto (BIZERRIL, 2019; JESUS, 2017; DINIZ, 2019; OLIVEIRA; FERNANDES, 2020).

Assim, diante da necessidade de se efetivar a educação em saúde e ambiental no ensino formal, além da importância de divulgar informações sobre o meio ambiente e saneamento básico, este estudo teve como objetivo conhecer e analisar os conhecimentos, opiniões e necessidades de professores de escolas municipais de ensino fundamental sobre Educação Ambiental, saúde e saneamento básico.

\section{Método}

Trata-se de uma pesquisa descritiva, uma vez que visa investigar uma série de informações durante o trabalho de campo, buscando descrever os fatos e fenômenos de determinada realidade (GERHARDT; SILVEIRA, 2008). Também, se caracteriza por uma abordagem qualitativa, pois analisa a relação entre o participante e o objeto, ou seja, um mundo indissociável entre o mundo real e a subjetividade dos participantes. Nesse cenário, o pesquisador procura conhecer a complexa realidade do seu objeto de estudo no seu contexto real, aprofundando-se sobre a compreensão de determinado grupo social (FERNANDES; SACARDO, 2008)

Em São Carlos há nove escolas de ensino fundamental; porém, seis escolas aceitaram participar da pesquisa, os dados foram coletados no período de março de 2019 a dezembro de 2019.

O quadro docente das seis escolas participantes do estudo era composto por 155 professores que se dedicam ao ensino fundamental nos períodos matutino e vespertino; porém, 49 professores aceitaram participar da pesquisa e foram incluídos no estudo por estarem exercendo a função na unidade escolar há mais de três meses.

O convite para participação na pesquisa foi realizado em todas as escolas do munícipio, diretamente aos professores durante os Horários de 
Trabalho Pedagógico Coletivo (HTPC), com prévia autorização dos diretores responsáveis por cada escola de ensino fundamental. A recusa de professores para participar da pesquisa estava associada ao horário destinado ao HTPC, que é realizado no período noturno e pós expediente, sendo assim, parte dos professores preferiram não participar devido a outros compromissos. Também, outros professores não participaram da pesquisa alegando cansaço devido à exaustiva jornada de trabalho.

Os dados foram coletados por meio de grupo focal, que consistiu em uma discussão entre os participantes sobre o tema da pesquisa, recebendo estímulos apropriados para o debate. A técnica do grupo focal propicia a interação grupal, aproximação, troca de experiências, e proporciona descontração para que os participantes possam responder as questões em grupo, em vez de individualmente (RESSEL et al., 2008).

Para o direcionamento da discussão foi utilizado um instrumento semiestruturado contendo sete perguntas norteadoras que abordavam os temas sobre EA, SA, saneamento básico. As entrevistas foram gravadas, transcritas e devido às questões éticas foram enumeradas de 1 a 49.

Posteriormente, os dados foram analisados por meio de análise temática, que se desdobrou em três etapas: pré análise, exploração do material e tratamento dos resultados obtidos (MINAYO, 2002).

A partir da análise dos dados, identificaram-se lacunas relacionadas aos conhecimentos e práticas em EA e SA por parte dos professores, aos quais necessitam de suporte e atualização referentes a essas temáticas. Tal fato possibilitou a elaboração de uma cartilha didática com base em publicações técnicas e científicas sobre EA e SA direcionada para professores de ensino fundamental, que poderá ser utilizada como material de apoio nas atividades.

Este estudo foi aprovado pelo Comitê de Ética em Pesquisa da Universidade Federal de São Carlos, CAAE 08628819.6.0000.5504.

\section{Resultados e Discussão}

Para melhor interpretação dos dados os resultados foram agrupados em duas unidades temáticas, a saber: Conhecimentos sobre Educação Ambiental e saúde ambiental; e, práticas em EA e SA: dificultadores e facilitadores.

\section{Conhecimentos sobre Educação Ambiental e saúde ambiental}

Essa unidade temática apresenta $e$ analisa as definições $e$ compreensões apresentadas pelos professores sobre EA, bem como os conhecimentos e saberes desses profissionais com relação aos impactos do ambiente sobre a saúde das crianças. 
Quando os professores foram questionados sobre o conceito de EA, foram evidenciadas lacunas na conceitualização, uma vez que referiam a conceitos com base no senso comum.

Passar para os alunos a parte de conscientização e relação com o meio ambiente (P7).

Dentro da sala por exemplo, é perceber o ambiente com os alunos, conscientização... Falamos outras coisas quando são datas comemorativas (P24).

A compreensão de professores sobre EA pode estar relacionada ao desconhecimento teórico sobre a temática, sendo incapazes de estabelecer a definição do conceito, bem como suas interrelações e importância.

O significado e definição de EA ainda é pouco difundido, até mesmo por parte dos educadores, devido à ausência de formação específica durante a formação desses profissionais (CARMO, 2020). O termo conscientização, citado pelos professores, faz parte de um processo relacionado à prática em EA, que pode assumir função transformadora, orientando os indivíduos para que se tornem atores ativos na promoção do desenvolvimento sustentável (REIS; SÊMEDO, 2012). Contudo, pensar na EA associada apenas às questões de ecologia e preservação do meio ambiente é, acima de tudo, ausentar-se sobre o papel político e crítico desses educadores (JACOBI, 2003).

Apesar de desconhecerem as definições sobre a EA, os professores expressaram a sua finalidade. Todavia, tendo em vista uma discussão mais efetiva em sala de aula, deve-se considerar que a EA não se baseia apenas na conscientização ambiental e preservação do meio ambiente, mas visa a construção de ideais interdisciplinares que justifiquem sua importância para a qualidade de vida e saúde das pessoas.

Ademais, outros discursos apresentaram concepções ampliadas sobre a forma com que o tema meio ambiente está sendo abordado em sala de aula, contudo não foi evidenciada a conceitualização da EA nesse processo, foco da pergunta direcionada aos professores.

Eles terem essa consciência de que o ambiente não é só tipo... a natureza, por que quando você fala em ambiente eles pensam na natureza, mas o ambiente é tudo, é tipo... a cidade, tudo faz parte do ambiente. Essas relações que estão ligadas entre os seres vivos, a natureza (P4).

EA até hoje eu conheço ligada as questões da ecologia, ambiental de fazer parte do ecossistema, plantas... Mas pensar em EA na questão de ambiente mesmo, nesse sentido é algo novo. Pensar no ambiente como algo saudável e eu ainda não estou acostumado, algo que eu não costumo pensar (P27).

Tendo em vista a interdisciplinaridade do tema meio ambiente e sua aplicação com a EA, as falas dos professores ainda aparecem de forma 
superficial. A ideia de que o homem faz parte e pode interferir sobre o equilíbrio do meio ambiente é evidenciada em algumas falas, contudo a sua associação com a saúde ainda não é evidente. Esse mesmo cenário é confirmado em um estudo realizado no Rio Grande do Sul, onde apenas 30\% dos professores apresentavam uma visão integral e complexa de meio ambiente (COSTA; NOBRE; FARIA, 2018).

Apesar da relevância e disseminação da EA no mundo, no Brasil, ainda não é desempenhada de maneira integral e efetiva no ambiente escolar, sendo direcionada à temas que expressam a relação do homem com o meio ambiente de forma superficial. Nesse contexto, a formação profissional dos professores deve ser revista, visando qualificá-los para a prática educacional de forma abrangente e crítica, tendo como arcabouço teórico as políticas educacionais, além de incluir as questões ambientais.

Em contrapartida, alguns professores apresentaram conceitos amplos de EA, considerando a relação entre os indivíduos e o meio ambiente, bem como os impactos na saúde e a importância da sustentabilidade.

EA pra mim é a compreensão de que tudo o que a gente faz afeta alguma coisa dentro do sistema, a gente vive em um sistema com ciclos e com seres vivo, então tudo o que a gente faz afeta esse sistema de alguma maneira, como uma teia onde tudo tá conectado. O lixo que eu jogo no chão causa uma implicação, mas não só isso, a relação que eu estabeleço com as pessoas também tem outras implicações... Acho que EA vai pra muito além de só falar do meio ambiente, envolve também a relação que a gente tem com o meio ambiente, que sempre veio crescendo como uma relação de exploração unicamente, também envolve compreender essa relação. Essa relação de como eu tiro, mas como eu também devolvo ou também uso, mas uso de maneira adequada, de maneira... como posso falar...sustentável (P18).

Isso é EA, né?! A educação para a relação com a natureza. O que é o ambiente, o que é a natureza, mesmo que construído pelo homem, mas como é essa construção. Daí quando você fala de saúde e saneamento básico, como as coisas são construídas no ambiente para que ela não destrua o ambiente natural? Então como o ser humano deve agir para que haja esse equilíbrio, ter a construção do ambiente natural para que possa promover a saúde (P48).

Diante dos resultados é possível inferir que parte dos professores possuem conhecimento amplo sobre a compreensão de EA, por outro lado, uma parcela considerável ainda articula o conceito teórico de EA com práticas educacionais, além de relacioná-la apenas à preservação da natureza e meio ambiente. Essa realidade faz refletir sobre a formação dos professores, ou seja, como a EA está inserida na formação acadêmica. Ressalta-se que essas lacunas na formação dos docentes impactam diretamente o processo de trabalho e metodologias direcionadas ao ensino de EA.

A informação transmitida pelo educador deve promover de forma satisfatória o ensino e aprendizagem em EA e saúde, todavia os professores 
devem estar atualizados e capacitados para atuarem como mediadores, apresentando domínio sobre as interfaces e aplicações da EA.

Ressalta-se que, a formação profissional inicial dos professores, em sua maioria constituída por um modelo educacional conservador, não atende as demandas atuais relacionadas à EA (RODRIGUES; SEHAB, 2019), justificando a dificuldade apresentada pelos mesmos. A falta de capacitação e educação permanente de professores do ensino básico, no que tange a abordagem da $E A$, impacta sobre as práticas escolares, especialmente no que se refere a abordagem de conteúdos relacionados aos impactos sociais e à saúde, as quais pouco são abordados em sala de aula.

Observa-se que há unanimidade entre os professores sobre a relevância e desenvolvimento da EA no ensino formal, contudo, mesmo diante do reconhecimento sobre a importância da inserção da temática no ambiente escolar, ainda não há uma implementação efetiva da mesma, de forma que relacione os aspectos sociais, além do potencial de transformação dos agentes envolvidos.

Apesar da lacuna do conhecimento sobre os conceitos de EA, os professores afirmaram ter ciência sobre os impactos ambientais e suas consequências na saúde, bem como sobre a importância e articulação da EA na conscientização das crianças sobre a relação entre meio ambiente e saúde. Contudo, alguns participantes afirmaram que SA está associada a prática de hábitos higiênicos.

Eles têm carência de necessidades muito básicas, as vezes a criança vem com roupa suja (P36).

Quando eles vão comer, vão direto e voltam direto, entram no banheiro sem lavar as mãos, não escovam o dente e nem nada (P12).

A associação de hábitos inadequados de higiene pessoal e coletiva como um dos principais problemas ambientais que afetam a saúde foi expressado por parte dos professores, sendo enfatizada a necessidade de se trabalhar tais questões no ambiente escolar. A concepção higienista se consolidou historicamente como forma de promoção à saúde no ambiente escolar, contudo a relação entre meio ambiente e saúde é complexa e vai além de ações isoladas e reduzidas a higiene pessoal.

A relação entre $S A$ e higiene é uma concepção social, presa ao movimento higienista, que se tornou culturalmente forte há décadas e ainda se mantêm vigente. Todavia, a naturalização de medidas higiênicas como forma de promoção à saúde ainda é pautada como sendo próprias da atualidade e relacionadas às problemáticas de saúde e meio ambiente (COLOMBANI; MARTINS, 2017).

Práticas de higiene pessoal e coletiva devem ser estimuladas e são importantes durante as práticas de EA e saúde, todavia devem ser empregadas 
de forma crítica e não serem reforçadas apenas como hábito diante à prevenção de doenças infecciosas, visto que, apenas práticas de higiene pessoal não contemplam as problemáticas referentes ao tema, como por exemplo a carência de acesso a serviços de saneamento no Brasil. Tal fato impacta negativamente na formação ambiental das crianças, as quais estarão condicionadas a relacionar conceitos higiênicos à SA.

Sendo assim, os profissionais que atuam no âmbito da EA devem estar preparados a trabalharem novos pensamentos e valores socioambientais, a fim de compreender as diversas associações, não limitando-se a conceitos pouco abrangentes (AVELAR, 2019). É importante que sejam realizadas práticas em EA que visem a integração do tema higiene de forma ampliada no cotidiano escolar, a partir da discussão sobre a higienização de ambientes e acesso a recursos de saneamento ambiental, como coleta de esgoto, tratamento de água e coleta de resíduos.

Em relação aos riscos que o ambiente oferece à saúde da criança, os professores apresentaram três principais expressões: queimadas, resíduos e dengue. As queimadas foram apontadas como maléficas à saúde da criança e relacionadas com a negligência ao meio ambiente, evidenciando a necessidade de inserção do tema no ambiente escolar.

$E$ as queimadas também, aqui é um lugar muito propicio para as queimadas, 0 pessoal coloca fogo em tudo e o tempo seco favorece as alergias, problemas respiratórios. Quase todo dia a tarde eu chegava aqui e tinha foco de queimada, então já discutia na hora com eles sobre os malefícios disso (P11).

Sim, até quando teve as queimadas na Amazônia, coincidiu com o conteúdo de vegetação que a gente estava estudando e aí eles trouxerem muitas coisas que eles viam na TV, que o pais falavam, o fato de a Amazônia ser longe. Discutimos bastante, depois teve aquela escuridão em São Paulo e aprenderam que tudo isso influencia (P30).

Para os professores, a problemática ambiental relacionada às queimadas e seus impactos à saúde são compreendidas facilmente pelos alunos, pois é vivenciada na comunidade e abordada pela mídia. Diversos fatores podem desencadear ou agravar quadros de doenças respiratórias nas crianças, principalmente a poluição atmosférica e alterações climáticas. Estimase que $30 \%$ das doenças que mais acometem crianças no mundo estão relacionadas aos fatores ambientais, sendo que, $40 \%$ das crianças afetadas têm idade inferior a cinco anos (SANTOS et al., 2017). As doenças respiratórias, associadas principalmente às ações antrópicas como as queimadas, são responsáveis pelo aumento do índice de internação e morbimortalidade no mundo, sendo o principal fator de risco associado a incidência e hospitalização de crianças por doenças respiratórias no Brasil (BEBBER et al., 2020). 
Adiante, identificou-se que os resíduos foram considerados pelos professores como um dos agravantes à saúde da criança; sendo referidas situações que foram vivenciadas no cotidiano escolar.

Tem uma aluna dessa escola que a família a leva pra catar lixo, eles são catadores e volta e meia eles levam ela, eu até já alertei a mãe de que não pode levar ela, e assim, semana passada ela pegou uma virosa, eu tenho certeza que é vasculhar lixo com a família. Por conta disso ela faltou na escola 3 dias, teve virose, teve diarreia, teve que ir ao hospital tomar soro, com certeza é porque a família leva ela pra catar lixo, e a mãe tem certa consciência de que não pode colocar a mão suja de lixo na boca, já a criança (P31)...

Eu trabalhava em uma escola que uma aluna ficou abrigada um por tempo, e ela só retornou para a casa do avô porque ele fez um acordo com a assistência social e ele era um catador de lixo, de que ele faria uma limpeza na casa porque acumulava lixo lá, mas ele não conseguiu fazer a limpeza (P41).

Além do descarte inadequado de resíduos, os professores relacionaram a problemática com a vulnerabilidade socioeconômica dos alunos, uma vez que alguns familiares realizavam coleta informal de resíduos e os acumulavam nas residências. A problemática relacionada ao descarte de resíduos não foi associada apenas com a preocupação com o meio ambiente, mas despertou reflexões quanto aos impactos à saúde, em especial dos escolares.

O discurso sobre a dengue esteve presente na fala dos professores, visto que surtos de dengue são frequentes no município, e a inclusão e relação entre os temas resíduos e dengue, no contexto da EA pode propiciar mudanças quanto ao atual cenário, visto que as crianças poderão desenvolver atitudes ambientalmente adequadas e sustentáveis desde a infância.

Nesse contexto, o descarte e acúmulo de resíduos em locais inapropriados propiciam criadouros de vetores, insetos e animais peçonhentos que podem ocasionar doenças infecciosas ou parasitárias, oferecendo riscos à saúde das crianças, as quais estão em cenário de maior vulnerabilidade socioambiental (GAVIOLI, 2019). Por outro lado, ressalta-se que áreas com menores taxas de vulnerabilidade socioambiental são as que têm maior implantação dos serviços de saneamento básico (DIAZ; SILVA; GRIGIO, 2021).

As arboviroses estão associadas não apenas a poluição do meio ambiente, mas também à ausência de serviços de esgotamento sanitário que propiciam o desenvolvimento de vetores e impactam na qualidade de vida e saúde das pessoas. Nesse contexto, a globalização do acesso a serviços básicos de saneamento, bem como a EA podem promover melhoras nos contextos ambiental e de saúde da população, a curto, médio e longo prazo.

O Novo Marco Legal do Saneamento Básico no Brasil, aprovado em 2020, tem como objetivo garantir o acesso universal à água potável, destinação adequada dos resíduos, coleta e tratamento de esgoto até dezembro de 2033. Atualmente, 39 milhões de brasileiros ainda não possuem acesso a água 
tratada e 101 milhões carecem de coleta de esgoto (BRASIL, 2020). O Novo Marco Legal do Saneamento Básico também visa a implementação dos serviços de saneamento básico para a população brasileira, uma vez que o prazo para universalização desses serviços e a extinção dos lixões a céu aberto foram prorrogados, e, não atingiram as metas estabelecidas na Política Nacional de Resíduos Sólidos e de Saneamento Básico.

A desigualdade provocada pela dificuldade de acesso aos recursos de saneamento básico afeta, principalmente, as populações mais vulneráveis; e, atualmente, impacta na disseminação da Covid-19, uma vez que a falta de acesso universal à água e tratamento de esgoto podem dificultar o enfrentamento dessa e de outras doenças (MELLO; VILARDI; MELLO, 2020).

Nesse contexto, o Novo Marco Legal do Saneamento Básico pode impactar positivamente sobre a saúde e qualidade de vida da população, uma vez que a implementação efetiva dos serviços de saneamento básico visa promover mudanças sobre o atual cenário epidemiológico do país e minimizar a desigualdade no acesso aos recursos hídricos e de saneamento. Desse modo, a EA também deve desenvolver atividades para a promoção da saúde articulando com os conceitos sobre saneamento básico e condicionantes sociais, econômicos e ambientais que impactam diretamente na saúde (WHO, 2020).

Contudo, nota-se que parte dos professores apresentaram dificuldade em expressar como os impactos ambientais podem afetar a saúde da criança, por outro lado enfatizaram a relação entre higiene e saúde e deixaram de referir sobre a relação entre a falta de esgotamento sanitário e saúde. O desconhecimento sobre os impactos do ambiente na saúde da criança pode interferir sobre como as práticas em EA são executadas em sala de aula, se limitando apenas às ações específicas de higiene e datas comemorativas, tendo pouca efetividade sobre a promoção da saúde. A ausência de conteúdos que estimulem o pensamento crítico sobre a relação meio ambiente e saúde durante a formação inicial dos professores, justifica em partes, a falta de articulação desses temas em EA, bem como a falta de educação permanente.

\section{Práticas em Educação Ambiental e saúde ambiental: dificultadores e facilitadores}

As práticas em EA e SA tiveram como foco o desenvolvimento de cinco temas pré-definidos: meio ambiente, água, saneamento básico, resíduos e higiene. Sobre as ações direcionadas ao tema meio ambiente, destaca-se a preocupação com a preservação.

O ano passado eu fiz uma pesquisa com eles. Nós tiramos fotos ao redor, ao entorno da escola, pra observar como a própria comunidade lida na questão da preservação do ambiente que eles vivem (P9). 
A gente fala sobre a importância do meio ambiente, importância das árvores, corte das arvores, o que nos traz de prejuízo. Quase todos os anos eu passo um filme sobre isso para as minhas turmas e abro uma discussão (P32).

As atividades relacionadas à preservação do meio ambiente têm como objetivo informar sobre os acontecimentos relacionados ao esgotamento dos recursos naturais devido à constante exploração da natureza, motivando reflexões críticas sobre o desenvolvimento de atividades mitigadoras que garantam um desenvolvimento sustentável. Nesse contexto, a modificação do comportamento humano em relação a degradação ambiental necessita de alterações, tendo o processo educacional como precursor para uma sociedade mais consciente e sustentável.

O aprendizado sobre preservação ambiental e desenvolvimento sustentável está diretamente relacionado as melhorias em diversos aspectos da sociedade, sendo que, a EA pode favorecer o processo de conscientização das crianças sobre esses assuntos que impactam diretamente a saúde das pessoas. A abordagem de temas que se remetam a preservação do meio ambiente são essenciais tanto para a sustentabilidade do planeta para as futuras gerações quanto para a preservação da própria humanidade, visto que a proteção e preservação ambiental são essenciais para a manutenção da vida e saúde (MACHADO; GARRAFA, 2020).

$\mathrm{Na}$ discussão sobre as práticas em EA também foram abordadas as atividades relacionadas ao uso e importância da água, a qual foram consideradas essenciais pelos professores.

A água como constituição do corpo humano, a forma adequada e saudável de beber água, filtrada, fervida (P26).

Falamos da água, pra que serve, de onde ela vem, e percorremos todo esse caminho (P38).

A água é considerada um elemento primordial à saúde quando associada ao consumo adequado, alimentação e constituição do corpo humano. Todavia, reflexões sobre a utilização dos recursos hídricos e escassez devido às ações antrópicas não foram apontadas pelos professores. Nesse cenário, destaca-se o papel do professor como educador ambiental, desenvolvendo atividades que preparem os alunos para a adesão de condutas e hábitos adequados quanto ao uso racional da água.

As temáticas relacionadas à água devem ser trabalhadas de forma interdisciplinar, sendo necessário aprofundamento teórico sobre a disponibilidade, distribuição e qualidade da água para consumo humano. Ressalta-se a importância da distribuição e disponibilidade da água, bem como sua qualidade para consumo humano, fatores associados a disponibilidade de serviços de tratamento e esgotamento sanitário. 
A ausência de esgotamento sanitário também propicia doenças de veiculação hídrica, comprometendo a qualidade da água disponível para consumo e favorece o desenvolvimento de microrganismos potencialmente patógenos, principalmente em populações vulneráveis (CETESB, 2015).

As atividades em EA que abordem o tema água, devem estar associadas ao tema saneamento básico, uma vez que a conservação, recuperação e qualidade da água impactam sobre a condição de saúde das pessoas e está diretamente associada a disponibilidade de esgotamento sanitário. A EA deve dialogar não somente com as questões relacionadas à água, mas também estar associada à promoção da saúde, estimulando o papel político dos alunos na participação social sobre a gestão desse recurso (PICOLLI et al., 2016).

A temática sobre saneamento básico foi pouco explorada nos discursos dos professores.

O esgoto é necessário, o cuidado com ele, a água que coletada é a água que volta para a sua casa para beber. Tudo isso é um trabalho constante (P20).

É mais vídeo de lugares que não tem saneamento básico (silêncio). Os tipos de doenças (P46).

Diante dos resultados apresentados e considerando a importância dos serviços de saneamento básico para a promoção da saúde da criança, é evidente que os professores devem fortalecer os seus conhecimentos sobre a temática, para que possam orientar e estimular reflexões sobre a ausência desses recursos e seu impacto na qualidade de vida e saúde das pessoas, em especial das crianças.

É importante que os professores desempenhem tais atividades em sala de aula, pois o saneamento básico é um serviço de infraestrutura essencial para a promoção da saúde e sua ausência pode impactar nos indicadores de saúde (FERREIRA et al., 2016). A disponibilização de esgotamento sanitário altera as condições ambientais de uma determinada localidade, além de propiciar a prevenção de doenças, melhoria da qualidade de vida e promoção da saúde (FERREIRA; GARCIA, 2017).

Estudo realizado em Botsuana, mostrou que as crianças em ensino escolar de países em desenvolvimento estão mais vulneráveis às doenças relacionadas à falta de esgotamento sanitário (THAKADU et al., 2018). Além dos impactos sobre a saúde, a falta de saneamento básico também implica sobre o rendimento escolar de crianças que vivem em áreas sem coleta de esgoto, gerando atraso escolar de $1,4 \%$ a mais do que as crianças que dispõem desse recurso (INSTITUTO TRATA BRASIL, 2018).

O tema saneamento básico é interdisciplinar e transversal ao ensino de $E A$, e as atividades desenvolvidas pelos professores devem contemplar a sua importância para a saúde da criança, considerando questões e problemáticas 
socioambientais especificas sobre a ausência de saneamento básico, bem como desenvolver abordagens amplas que estimulem o pensamento crítico quanto à universalização desse serviço.

Tendo em vista que a saúde é pré-condição associada ao desenvolvimento de uma sociedade sustentável, é essencial que os Objetivos do Desenvolvimento Sustentável (ODS) sejam inseridos no contexto da abordagem sobre EA, considerando seus dezessete objetivos essenciais para a melhoria da saúde e qualidade de vida, inclusive o objetivo número seis, que refere à disponibilidade de água e saneamento básico para todos (CANELLAS, 2020).

Sobre as atividades práticas relacionadas à temática resíduos, os professores afirmaram desenvolver ações relacionadas à reutilização de materiais e reciclagem.

No quinto ano a gente foca nos 5 R's, o que é bastante envolvido com Educação Ambiental (P32).

Teve um projeto sobre conscientização do meio ambiente que a gente desenvolveu bastante atividades, teve uma que trazer o lixo pra separar o reciclável (P11).

Todos os anos nós fazemos o replantio de flores e algumas outras plantas, e daí eu trabalho novamente todo o conceito do projeto, a importância da reutilização, o que pode ser feito com pneus, como poder transformar esse pneu num vaso. (P40)

Práticas em EA sobre a reutilização e reciclagem configuram-se alternativas ao descarte excessivo e inadequado dos resíduos. Apesar da reciclagem e reutilização, tema mais citado entre os professores, ser importante para a conscientização da criança sobre a problemática dos resíduos, ainda há a necessidade de se explorar a importância da coleta seletiva, uma vez que contribui para minimizar a quantidade de resíduos descartados e pode ser uma fonte de renda para os catadores.

No Brasil são geradas 160 mil toneladas diárias de resíduos, sendo que $40 \%$ não são passiveis a processos de reaproveitamento e reciclagem, e dos $60 \%$ dos elegíveis, apenas $13 \%$ são encaminhados a reciclagem. Nesse contexto, as atividades referentes à reciclagem dos resíduos desenvolvidas durante a infância e inseridas como prática no dia a dia das crianças pode contribuir para mudanças no cenário ambiental, buscando familiarizar essa população quanto à separação e redução dos resíduos, bem como para a minimização dos impactos relacionados à saúde (INSTITUTO DE PESQUISA ECONÔMICA APLICADA (IPEA), 2017).

Uma pesquisa realizada no interior de São Paulo mostrou que os resíduos gerados em uma escola municipal de ensino básico eram destinados ao aterro sanitário, mesmo com a existência de coleta seletiva no local. Tal fato reforça a necessidade de se implementar de forma efetiva a separação de

revista brasileira educação ambiental 
resíduos e coleta seletiva nas escolas por meio do ensino em EA, visto que estimula as crianças a se habituarem com a prática de segregação dos resíduos tanto no ambiente escolar como na comunidade. O desenvolvimento dessas atividades pode proporcionar benefícios ao meio ambiente por meio da reciclagem, disposição final dos resíduos e a minimização dos impactos gerados à saúde (SOFA; LOPES, 2020).

Nesse contexto, a EA é ferramenta essencial na instrução e conscientização dos indivíduos diante a importância da separação dos resíduos e da reciclagem. $O$ trabalho desenvolvido em sala de aula contribui para a formação das crianças sobre os benefícios da coleta seletiva, e, indiretamente sobre o consumo sustentável e racional. Por outro lado, professores afirmaram que não realizam atividades práticas sobre a separação dos resíduos e coleta seletiva devido à infraestrutura precária do ambiente escolar.

Não trabalho porque o lixo que a gente produz aqui é basicamente papel (P41).

Por exemplo, nós não temos lixeiras específicas, e tudo isso atrapalha a prática dessas ações (P13).

A falta de coleta seletiva de resíduos aliada a falta de infraestrutura e domínio sobre a temática prejudicam a execução de atividades práticas. Contudo, esses argumentos apresentados por professores não justificam a exclusão do tema, visto que o aprendizado adquirido sobre segregação e destinação adequada dos resíduos não será reproduzido apenas no ambiente escolar, mas no convívio em sociedade, sendo fundamental para a formação de cidadãos orientados sobre o desenvolvimento de ações sustentáveis.

As áreas urbanas registram baixas taxas de reciclagem, em detrimento da elevada geração e disposição final inadequada dos resíduos (KNICKMEYER, 2020). Nesse contexto, o conhecimento sobre a classificação dos resíduos, aliado a importância da coleta seletiva devem ser foco nas atividades em EA, uma vez que contribuem para a conscientização sobre os impactos do descarte inadequado dos resíduos.

Por fim, atividades sobre higiene foram mencionadas pelos professores como sendo práticas essenciais no âmbito da saúde e EA.

Mas a questão da higiene, assim, sempre é muito trabalhada, porque sempre acontece alguma coisa (P7).

Higiene principalmente, a todo momento. Lavar as mãos depois de ir ao banheiro, antes de ir pro refeitório, hora que eles voltam da educação física (P19). 
inseridas no contexto de formação escolar, em especial durante à formação infantil, contudo, as ações de promoção à saúde vinculadas à EA não se baseiam apenas na concepção de hábitos higiênicos, e devem abranger as problemáticas ambientais e de saúde associadas.

Nesse contexto, destaca-se a higiene ambiental, que se configura como práticas que visam a preservação das condições sanitárias do ambiente, a fim de que fatores externos, sejam químicos, físicos ou biológicos não causem prejuízos à saúde. A higiene ambiental objetiva a criação de ambientes propícios à saúde e não tem foco apenas na prevenção de doenças (JANTSCH, 2011).

A realização de práticas em EA visa a inserção do tema higiene de forma ampliada no cotidiano escolar, a partir da reflexão de que o acesso a recursos de saneamento ambiental propicia à promoção da saúde por meio do acesso a serviços como coleta de esgoto, tratamento de água e coleta de resíduos.

Para os professores o acúmulo excessivo de trabalho, falta de investimento do poder público e lacunas na formação profissional são considerados fatores dificultadores para o desenvolvimento de atividades práticas sobre EA.

Temos muitos conteúdos pra trabalhar, e é raro a gente conseguir um tempo pra trabalhar isso especificamente, do jeito que deveria, pelo menos nos primeiros anos, é sempre fazendo um gancho, o foco é outro, o foco é alfabetizar (P27).

Tudo o que trazemos para as aulas é nosso, investimentos todos próprios, isso dificulta. Tem um pouco de material didático, mas ainda temos que correr atrás (P29)!

Quando parte para a prática é que complica, os passeios e os materiais que muitas vezes a gente não tem disponibilizado (P7).

Lá atrás quando eu me formei, EA era abordada em metodologia das ciências, isso lá atrás, e era tratado outros vários assuntos, inclusive $E A$, mas de uma forma muito superficial (P09).

A associação dos fatores dificultadores contribui para um desenvolvimento insuficiente de atividades práticas em EA. Para os professores, o acúmulo de conteúdo a ser trabalhado durante o ano letivo perante a carga horária prejudicam a execução de práticas em EA. Contudo, mesmo diante das adversidades apresentadas pelos professores, os conteúdos que busquem a formação cidadã dos alunos não pode ser dispensados, especialmente ao considerar a importância da EA.

A necessidade de alfabetizar crianças inseridas no contexto da educação básica é priorizada diante o desenvolvimento de outras práticas específicas, como por exemplo saúde e EA. Esse fato implica sobre os conceitos e ações destinadas às crianças durante a aplicação de temáticas 
ambientais, as quais não são preestabelecidas pedagogicamente, sendo por vezes escassa. Ressalta-se, que a EA pode ser trabalhada transversalmente, ao mesmo tempo que desenvolve as atividades de alfabetização, mas para isso, necessita de capacitação dos profissionais envolvidos.

Os professores de ensino básico possuem jornadas de trabalho exaustivas, pois muitos se dedicam ao ensino de diferentes disciplinas. $O$ excesso de tarefas, baixa remuneração, falta de autonomia e infraestrutura do ambiente escolar podem ocasionar mal-estar físico e mental, influenciando negativamente na qualidade de vida desses profissionais (ROCHA; FERNANDES, 2008).

Estudo realizado com professores de ensino básico de Florianópolis evidenciou que a valorização profissional e melhoria das condições de trabalho foram as principais reinvindicações, além disso, foi destacado que o apoio social dentro do ambiente escolar propicia uma maior satisfação dos alunos (PEREIRA, 2014).

Nesse cenário, o Pacto Nacional pela Alfabetização na Idade Certa, proposto pelo Ministério da Educação, em 2012, tem como objetivo promover ações que possibilitem a alfabetização da criança até oito anos, determinando disciplinas específicas, como língua portuguesa e matemática como base prioritária (BRASIL, 2012). Contudo, a inserção de conteúdos sobre EA durante o processo de alfabetização pode configurar-se como um instrumento de sensibilização e leitura do mundo frente às transformações ambientais provenientes das ações humanas (SOUZA, 2018).

Outro fator importante mencionado pelos professores foi a falta de investimento do poder público na educação. Essa situação também interfere negativamente no desenvolvimento de todas as atividades escolares, devido à indisponibilidade de materiais a serem utilizados, ausência de visitas técnicas, falta de recursos para propiciar a realização de atividades práticas, além de interferir na motivação de professores e alunos.

Este estudo evidencia que mesmo frente à publicação da PNEA, o ensino de $E A$ em espaços formais ainda está se estabelecendo diante às normas estabelecidas pela Política Municipal de EA, uma vez que ainda se encontram lacunas referentes à implantação, financiamento, cumprimento e avaliação das ações no município.

Dentre os dificultadores, a falta de formação específica durante a formação inicial dos professores influencia na qualidade e desenvolvimento das práticas em EA que visem a abordagem de temas transversais, como por exemplo a relação entre saúde e meio ambiente.

A PNEA define que a questão ambiental deve constar nos currículos de formação dos professores, em todos os níveis e em todas as disciplinas, sendo que, os professores em atividade devem receber atividades de educação permanente. Contudo, os professores em exercício do município alegam que não participam dessas atividades destinadas ao exercício da EA. 
A inserção da educação permanente na formação de professores, permite o rompimento de barreiras sobre a prática linear de ensino, provocando reflexões que resultem em modificações da prática em EA (COLOMBANI; MARTINS, 2017). Com isso, a educação permanente dos professores favorece a superação de desafios que envolvam as práticas de EA, possibilitando que a formação inicial e inespecífica não se limite a oportunidade de buscar novos conhecimentos que aperfeiçoem as ações destinadas ao aprendizado ambiental.

Em relação aos fatores facilitadores do desenvolvimento de atividades de EA e saúde, os professores mencionaram a participação e interesse dos alunos e a disponibilidade de livros didáticos

A facilidade, ao meu ver, é que eles aceitam muito bem, eles gostam, eles entendem, eles se envolvem (P20).

A facilidade são os livros que encontramos disponíveis (P42)

A participação e interesse dos alunos durante as atividades práticas de EA e saúde infere na importância da dinamicidade de métodos a ser utilizados no processo de ensino-aprendizagem, extrapolando o ambiente da sala de aula, além de investir na pró-atividade e criatividade de cada criança.

Estudo realizado na cidade de Natal mostrou que a tomada de consciência sobre atitudes ambientalmente sustentáveis tem como fator chave a participação dos alunos, contudo, as atividades promovidas devem sempre ser avaliadas quanto à efetividade e revisadas, buscando maior participação e envolvimento dos alunos (AZEVEDO, 2013).

As práticas em EA e saúde configuram-se como uma ferramenta para a transformação da realidade social, sendo que, a atuação direta do aluno nas atividades propostas pode propiciar maior efetividade em situações que necessitem mudança.

O acesso facilitado aos livros didáticos referido pelos professores também pode estar relacionado à comodidade de não ter que realizar buscas constantes de materiais para organizar um conteúdo. Contudo, é indicada a realização de uma avaliação criteriosa dos materiais utilizados em sala de aula, em especial de livros didáticos, visto que a utilização desse instrumento como único suporte as práticas de EA não garante a reprodução de conteúdos satisfatórios (TONIN, UHMANN, 2020).

Atualmente, deve-se considerar a utilização de recursos tecnológicos, especialmente a internet, como um fator facilitador para a elaboração de conteúdos sobre EA e SA; principalmente, articulando as notícias sobre a temática com os conceitos. Estudo realizado em Paraíso do Norte, Paraná, mostrou que o uso de recursos audiovisuais pode facilitar a construção do conhecimento em sala de aula, sendo uma importante alternativa para captar a atenção do aluno (SANTOS et al., 2020). 
Destaca-se, que diante o cenário atual, há necessidade crescente de se investir cada vez mais na qualidade e disponibilização de materiais online que propiciem o aprendizado em EA e SA, haja vista o crescimento do ensino remoto no país, potencializado pelo cenário da pandemia da Covid-19.

\section{Conclusões}

Os professores apresentaram dificuldades para definir os conceitos de EA e SA; porém, afirmaram conhecer os impactos ambientais e suas implicações na saúde da criança. As práticas em EA com relação aos temas como meio ambiente, água, saneamento básico e resíduos também foram abordadas pelos professores, contudo necessitam ser exploradas de forma transversal e integral, tendo em vista sua relevância para sustentabilidade e os impactos na saúde.

O desconhecimento dos professores sobre as definições de EA e SA e suas práticas associado aos fatores dificultadores direciona para a necessidade da inserção dessa temática na graduação desses profissionais, bem como o desenvolvimento de atividades de educação permanente, além da criação de políticas públicas que potencializem as ações de ensino sobre EA e SA, contribuindo para a promoção da saúde e formação de cidadãos conscientes sobre a sustentabilidade ambiental.

\section{Agradecimentos}

À Fundação de Amparo à Pesquisa do Estado de São Paulo (FAPESP), pelo apoio financeiro durante o desenvolvimento da pesquisa; à Secretária Municipal de Educação de São Carlos pela viabilização da pesquisa.

\section{Referências}

AVELAR, M.C. et al. Educação Ambiental e interdisciplinaridade: da formação inicial à prática pedagógica na educação básica. 100 f. Dissertação - Curso de ciências ambientais, Universidade Federal do Pará, Belém, 2019.

AZEVEDO, A.K. et al. A Educação Ambiental e sua influência nas atitudes de alunos de uma escola de ensino fundamental de Natal/RN. Revista de Engenharia Ambiental: Pesquisa e Tecnologia. Espírito Santo do Pinhal, v. 9, n. 4, 2012.

BEBER, L.C.C. et al. Fatores de risco para doenças respiratórias em crianças brasileiras: revisão integrativa. Revista Interdisciplinar de Estudos em Saúde, Universidade Alto Vale do Rio do Peixe, v. 9, n. 1, 2020.

BIZERRIL, M.; FARIA, D.S. Percepção de professores sobre a Educação Ambiental no ensino fundamental. Revista Brasileira de Estudos Pedagógicos, v. 82, n. 200, 2001. 
BRASIL, Senado Federal. Lei ํo 9.795, de 27 de abril de 1999. Política Nacional de Educação Ambiental. Brasília, DF: Senado Federal, 1999. Disponível $<$ http://www.mma.gov.br/port/conama/legiabre.cfm?codlegi=321> Acesso em: 10 out. 2019.

BRASIL. Ministério da Educação. Secretaria da Educação Básica. Pacto Nacional pela Alfabetização na Idade Certa. Cadernos de Formação. Brasília, DF: MEC/SEB, 2012.

BRASIL, Senado Federal. Senado aprova novo marco legal do saneamento básico. Fonte: Agência Senado. Brasília, DF: Senado Federal, 2020. Disponível em: $<$ https://www12.senado.leg.br/noticias/materias/2020/06/24/senado-aprovanovo-marco-legal-do-saneamento-basico.> Acesso em: 01/04/2020

CANELLAS, K. Os objetivos do desenvolvimento sustentável (ODS) e suas metas. Editora Clima em Curso, 2020. Disponível em: <http://200.137.241.24:8081/jspui/bitstream/123456789/232/1/ODS.pdf.> Acesso em: 20/03/2020

CARMO, A.M.R. et al. Educação Ambiental no Projeto Político Pedagógico: um caminho para promover a sustentabilidade. $81 \mathrm{f}$. Dissertação - Curso de Mestrado Profissional em Planejamento Ambiental, Universidade Católica do Salvador, Salvador, 2020.

CARRARO, E.C.; MILITÃO, E.C.; VIANA, H.B. A percepção dos educadores quanto ao seu papel na promoção de hábitos e estilos de vida saudáveis no ambiente escolar. Revista da Faculdade de Educação, Universidade do Est. do Mato Grosso, v. 32, n. 2, p. 189-213, 2019.

CETESB, Companhia Ambiental do Estado de São Paulo. Surtos de doenças de veiculação hídrica. 2015. Disponível em: $<$ http://laboratorios.cetesb.sp.gov.br/atendimento-a-emergencia/surtosdedoencas-de-veiculacao-hidrica/> Acesso em: $01 \mathrm{fev} .2020$.

COLOMBANI, F.; MARTINS, R.A. O movimento higienista como política pública: aspectos históricos e atuais da medicalização escolar no Brasil. Revista online de Política e Gestão Educacional, Araraquara, v.21, n.1, p.278-295, 2017.

COSTA, R.D.A. et al. Paradigmas da Educação Ambiental: análise das percepções e práticas de professores de uma rede. Revista Electrónica de Enseñanza de las Ciencias, v. 17, n. 1, p. 248-262, 2018.

DIAS, G.H.; SILVA, M.R.F.; GRIGIO, A.M. Vulnerabilidade ambiental: uma abordagem sobre a exposição ao risco e a degradação ambiental em Mossoró/RN-Brasil. Brazilian Journal of Development, Curitiba, v. 7, n. 2, p. 17199-17216, 2021.

DINIZ, K.S. Educação Ambiental na Educação Infantil: a percepção dos professores da educação infantil da Escola Municipal de Educação Infantil 
Patrimônio, em Uberlândia-MG. 22 f. Dissertação - Curso de Gestão em Saúde Ambiental, Universidade Federal de Uberlândia, Uberlândia, 2019.

FERREIRA, M.P.; GARCIA, M.S.D. Saneamento básico: meio ambiente e dignidade humana. Dignidade Re-Vista, v. 2, n. 3, p. 12, 2017.

FERREIRA, P.S.F. et al. Avaliação preliminar dos efeitos da ineficiência dos serviços de saneamento na saúde pública brasileira. Revista internacional de ciências, Rio de Janeiro, v. 6, n. 2, p. 214-229, 2016.

FRANÇA, E.B. et al. Principais causas da mortalidade na infância no Brasil, em 1990 e 2015: estimativas do estudo de Carga Global de Doença. Revista brasileira de epidemiologia, v. 20, p. 46-60, 2017.

GAVIOLI, O. Aedes aegypti e Aedes albopictus e sua relação com materiais descartados em jardins de unidades do Quadrelátero de saúde na cidade de São Paulo. 115 f. Dissertação - Curso de Saúde Pública, Universidade de São Paulo, São Paulo, 2019.

INSTITUTO TRATA BRASIL. O saneamento básico para a saúde da criança no Brasil. 2018.

JACOBI, P. Educação Ambiental, cidadania e sustentabilidade. Cadernos de pesquisa, São Paulo, n. 118, p. 189-206, 2003.

JANTSCH, L.B. et al. Conversando com adolescentes sobre higiene ambiental. Revista Contexto Saúde, Santa Maria, v. 10, n. 20, p. 841-846, 2011.

JESUS, R.A.; FIGUEIREDO, G.O. Percepção de professores do ensino fundamental sobre educação em saúde na prática pedagógica de uma escola pública. In: XI Encontro Nacional de Pesquisa em Educação em Ciências, 2017, Florianópolis. Anais, SP: ABRAPEC, 2017.

KNICKMEYER, D. Social factors influencing household waste separation: A literature review on good practices to improve the recycling performance of urban areas. Journal of cleaner production, v. 245, p. 118, 2020.

MACHADO, I.L.O.; GARRAFA, V. Proteção ao meio ambiente e às gerações futuras: desdobramentos e reflexões bioéticas. Revista Saúde em Debate, Rio de Janeiro, v. 44, n.124, p. 263-274, 2020.

MINAYO, M.C.S.; MIRANDA, A.C. Saúde e ambiente sustentável: estreitando nós. Rio de Janeiro, Editora Fiocruz, 2002.

MELLO, R.R.P.B. et al. Desafios no acesso à água e saneamento básico no Brasil e o controle da Covid-19. Revista Augustus, Rio de Janeiro, v. 25, n. 51, p. 281-293, 2020.

OLIVEIRA, N.S. et al. Educação Ambiental como promotora da saúde: revisão integrativa da literatura. Revista Saúde e Meio Ambiente, Três Lagoas, v. 10, n. 1, p. 175-188, 2020.

PEREIRA, E.F. et al. Associação entre o perfil de ambiente e condições de trabalho com a percepção de saúde e qualidade de vida em professores de 
educação básica. Cadernos de Saúde Coletiva, Rio de Janeiro, v. 22, n. 2, p. 113-119, 2014.

PERLROTH, N.H.; BRANCO, C.W.C. Current knowledge of environmental exposure in children during the sensitive developmental periods. Jornal de pediatria, Rio de Janeiro, v. 93, n. 1, p. 17-27, 2017.

PHILIPPI JÚNIOR, A.; MALHEIROS, T.F. Saúde ambiental e desenvolvimento. In: Educação Ambiental e sustentabilidade. Barueri, São Paulo: Ed. Manoele, Cap 4, p. 59-83, 2005.

PHILIPPI JÚNIOR, A.; MALHEIROS, T.F. Saúde ambiental e desenvolvimento. In: Educação Ambiental e sustentabilidade. Barueri, São Paulo: Ed. Manoele, Cap 1, p. 3-31, 2005.

PICCOLI, A.S. et al. A Educação Ambiental como estratégia de mobilização social para o enfrentamento da escassez de água. Ciência \& Saúde Coletiva, Rio de Janeiro, v. 21, n. 3, p. 797-808, 2016.

REIGOTA, M. A Educação Ambiental como educação política. In: O que é Educação Ambiental, São Paulo: Ed. Brasiliense, v. 1, p. 11-19, 2009.

REIS, L.C.L.; SEMÊDO, L.T.A.S.; GOMES, R.C. Conscientização ambiental: da educação formal a não formal. Revista Fluminense de extensão universitária, Vassouras, v. 2, n. 1, p. 47-60, 2012.

RESSEL, L.B. et al. O uso do grupo focal em pesquisa qualitativa. Texto \& Contexto-Enfermagem, Florianópolis, v. 17, n. 4, p. 779-786, 2008.

ROCHA, V.M.; FERNANDES, M.H. Qualidade de vida de professores do ensino fundamental: uma perspectiva para a promoção da saúde do trabalhador. Jornal Brasileiro de Psiquiatria, Rio de Janeiro, v. 57, n. 1, p. 2327, 2008.

RODRIGUES, D.G.; SAHEB, D. A formação continuada do professor de Educação Infantil em Educação Ambiental. Ciência \& Educação, Bauru, v. 25, n. 4, p. 893-909, 2019.

SANTOS, D.A.S. et al. A relação das variáveis climáticas na prevalência de infecção respiratória aguda em crianças menores de dois anos em Rondonópolis-MT, Brasil. Ciência \& saúde coletiva, v. 22, p. 3711-3722, 2017.

SANTOS, E.O. et al. O uso da tecnologia em sala de aula para fins pedagógicos. Revista Científica Multidisciplinar, Paraíso do Norte, v. 1, n. 1, p. 106-118, 2020.

SILVA, C.S.; BODSTEIN, R.C.A. Referencial teórico sobre práticas intersetoriais em Promoção da Saúde na Escola. Ciência \& Saúde Coletiva, v. 21, n. 6, p. 1777-1788, 2016. 
SILVA, J.R. Políticas Públicas Para O Saneamento Básico Nacional: A Problemática Da Universalização. Revista Cadernos de Economia, Chapecó, v. 21, n. 37, p. 87-109, 2017.

SILVEIRA, D.T.; CÓRDOVA, F.P. A pesquisa científica. Métodos de pesquisa. Porto Alegre: Editora da UFRGS, p. 17-20, 2009.

SOFA, A.P.; LOPES, M.M. A Educação Ambiental na escola e a separação de resíduos sólidos: relato de uma experiencia na educação básica. In: Educação e Tecnologia em Debate: perspectivas sob diferentes áreas do conhecimento. São Carlos: Pedro \& João Editores, p. 23-39. 2020.

SOUZA, A.Q.. Educação Ambiental e Paulo Freire: Anunciação de um Letramento Ambiental. Revista Latino-Americana de Estudos em Cultura e Sociedade, v. 4, 2018.

THAKADU, O.T. et al. Sanitation and hygiene practices among primary school learners in Ngamiland district, Botswana. Physics and Chemistry of the Earth, Parts A/B/C, v. 105, p. 224-230, 2018.

TONIN, L.H.; UHMANN, R.I.M. Educação Ambiental em livros didáticos de Ciências: um estudo de revisão. Revista Brasileira De Educação Ambiental, v. 15, n. 1, p. 245-260, 2020.

WORLD HEALTH ORGANIZATION. School and youth health: what is a health promoting school? Disponível em: $<$ http://www.who.int/school youth health/gshi/hps/en/> (acessado em 06/abril/2020) 